\title{
A utopia brasileira da mídia cidadã
}

José Marques de Melo

Professor emérito da Escola de Comunicações e Artes da Universidade de São Paulo.

Professor da Universidade Metodista de São Paulo, onde dirige a Cátedra UNESCO

de Comunicação. Autor de, entre outros, Midiologia para Iniciantes (EDUCS, 2005)

$e$ Teoria do Jornalismo (Paulus, 2006) ${ }^{1}$.

E-mail: marquesmelo@uol.com.br

Cidadania e Utopia são conceitos que brotaram de uma mesma conjuntura histórica. Filhos diletos da modernidade, simbolizam produtos das liberdades urbanas que Braudel identifica como responsáveis pelo "primeiro surto desenvolvimentista" ${ }^{2}$ europeu.

A cidadania foi sendo conquistada em meio a tensões sociais e lutas de classes, gerando situações de incertezas, quando as cidades começaram a sofrer ameaças regulatórias por parte dos Estados modernos. Esses movimentos pendulares da vida cotidiana certamente motivaram Thomas Morus a satirizar as contradições da sua época. Concebendo a utopia como ilha imaginária, ele tornou a felicidade patrimônio coletivo.

Não obstante tenha sido contemporâneo do artífice do fenômeno social que hoje conhecemos pelo neologismo Mídia ${ }^{3}$, o criador da utopia não viveu o suficiente para conhecer a Galáxia de Gutenberg. Mas, se tivesse atravessado o portal do universo tipográfico, certamente desejaria recolher-se ardentemente ao seu refúgio utópico, tamanho o impacto provocado pela imprensa nos pilares da sociedade. Refletindo a intrepidez de cidadãos forjados pelo nacionalismo, individualismo e espírito de crítica ${ }^{4}$, a geografia européia expandiu suas fronteiras além-mar e a história intelectual percorreu caminhos infinitos.

Os detentores do poder, nos emergentes Estados nacionais, trataram de refrear o ímpeto da cidadania, da mesma forma que os guardiões da doutrina, no precursor Estado multinacional (Igreja Católica), não hesitaram em deter o poder revolucionário da imprensa. $\mathrm{E}$ as nefastas conseqüências da engrenagem inquisitorial perduraram durante séculos. Foram neutralizadas apenas quando a cidadania tornou-se hegemônica nos Estados regidos pela democracia representativa, fortalecida pelo ideário republicano. "O século que viu Colombo, viu Gutenberg também" , proclamou retoricamente Castro Alves no poema O livro e a América. Mas a coincidência foi mero acidente histórico, advertiu imediatamente o poeta: isso ocorreu "Por uma fatalidade. Dessas que descem de além" ${ }^{\text {. }}$

Tanto assim que o itinerário da mídia impressa no continente desbravado por Colombo obedeceu a uma seqüência plenamente articulada com o percurso aqui desenvolvido pela urbanização e pelo fortalecimento da cidadania ${ }^{7}$. Os

1. <http://www.marquesdemelo.pro.br>.

2. BRAUDEL, Fernand. Gramática das civilizações. São Paulo: Martins Fontes, 1989. p. 297-299.

3. MARQUES DE MELO, José. Midiologia para iniciantes. Caxias do Sul-RS: Educs, 2005. p. 13-22.

4. McLUHAN, Marshall. A Galáxia de Gutenberg. São Paulo: Nacional, 1972.

5. <http://www. bibvirt. futuro.usp.br/textos/autores/castroalves/espumas/ espumas_texto.html>.

6. Ibid.

7. MARQUES DE MELO, José. História social da imprensa. Porto Alegre: Edipucrs, 2003. p. 59-85. 
8. FREIRE, Paulo. Educação como prática da liberdade. Rio de Janeiro: Paz e Terra, 1966.

9. BELTRÃO, Luiz. Folkcomunicação. Porto Alegre: Edipucrs, 2001. p. 73.

10. MARQUES DE MELO, José. História social da imprensa..., op. cit.

11. Id. Subdesenvolvimento, urbanização e comunicação. Petrópolis: Vozes, 1976. p. 30-35.

12. Id. Comunicação e classes subalternas. São Paulo: Cortez, 1980.

13. Vide: RABAÇA, Carlos Alberto; BARBOSA, Gustavo. Dicionário de Comunicação. Rio de Janeiro: Campus, 2001. p. 505. prelos madrugam nos territórios conquistados pelo Império Castelhano (1533), onde os colonizadores reproduzem as condições de vida desfrutadas pelos cidadãos que habitavam os burgos da metrópole ibérica. Eles florescem mais tarde (1638) no espaço ocupado pela coroa britânica, justamente quando se intensifica a migração de comunidades religiosas. Elas constroem a malha urbana das colônias agroindustriais, em que as práticas cidadãs aceleram o processo de autonomia nacional. Fenômeno contrastante ocorre na vastidão territorial da Colônia lusitana, onde a mídia impressa foi retardada durante três séculos (1808), como decorrência da incipiente urbanização e da conseqüente ausência de cidadania, entre outros fatores de natureza sociocultural.

Não é sem razão que Paulo Freire deplora o "mutismo do homem brasileiro", resultante da nossa inexperiência democrática durante o regime colonial.

Desprovido de suportes midiáticos e destituído de referentes simbólicos que habilitassem ao ingresso na Galáxia de Gutenberg, o povo brasileiro foi criando sua própria mídia (artesanal, ardilosa, criativa). Trata-se do embrião da mídia cidadã, que ganharia densidade, mas não necessariamente legitimidade, na fase posterior à independência nacional. Luiz Beltrão (1967) denominou sistema de folkcomunicação ao conjunto dessas manifestações populares ${ }^{9}$. Na verdade, elas permanecem vivas até os dias atuais, coexistindo dialeticamente como o sistema de comunicação massiva.

\section{BRECHAS E ALTERNATIVAS}

Essa simultaneidade de sistemas midiáticos, um massivo (hegemônico) e outro popular (contra-hegemônico), configura paradoxo que desafia os pesquisadores da área de Comunicação.

Ele faz parte da minha agenda acadêmica desde o doutorado. A tese que defendi em 1973 tinha como objetivo principal a elucidação da defasagem temporal entre o funcionamento da mídia no continente europeu e nos territórios coloniais. As variáveis contempladas reforçavam a idéia de que a ausência de urbanismo e conseqüentemente de cidadania inibiu o desenvolvimento da mídia impressa ${ }^{10}$. Problematizei, no livro que reúne ensaios do pós-doutorado, o papel modernizador da mídia em sociedades que mantêm contingentes humanos à margem do desenvolvimento econômico. Anula-se completamente o estímulo à participação que a engrenagem midiática provoca nas audiências, tendo em vista a ausência do pleno exercício da cidadania ${ }^{11}$.

Retornei a essa questão na conjuntura da transição brasileira para o regime democrático, ao sugerir que as novas gerações de pesquisadores da área explorassem a mídia cultivada pelas classes subalternas. Em vez de estigmatizar como espaço de alienação política, testar a hipótese da resistência possível dos excluídos pela sociedade de consumo ${ }^{12}$. Sistematizei posteriormente as observações sobre a contra-hegemonia exercitada pela mídia nanica (expressão corrente em 1960-1970, designando os meios de comunicação de pequeno porte, sobretudo os tablóides e os jornais alternativos $)^{13}$, robustecendo a tese de que a imprensa 
comunitária brasileira, com raras exceções, pauta-se por critérios e motivações externos às comunidades a que servem. Ordenei também as minhas reflexões sobre a brecha cidadã existente em nossa sociedade, tomando como referência a pedagogia da comunicação de Paulo Freire ${ }^{14}$.

Contribuição relevante para decifrar o enigma da mídia cidadã no Brasil foi proporcionada pelo professor Luiz Beltrão, através do livro em que redimensiona e amplia o conceito de folkcomunicação. Identificando-o como mídia dos marginalizados, ele inventariou as formas rudimentares através das quais as classes subalternas expressam sua inconformidade em relação à sociedade instituída pelas camadas superiores. Coletando evidências em várias regiões do país, compôs um panorama unificado pela "universalidade que advém do folclore, desde que a autêntica cultura popular tem raízes, tronco e ramos tão profundamente arraigados na natureza humana"15.

Nessa mesma linha de resgate dos processos de comunicação popular, Ribeiro Júnior percorreu a trilha das festas populares, conceituando-as pedagogicamente como espaços de resistência cultural, nos quais a função lúdica não exclui as contradições sociais ${ }^{16}$. $\mathrm{O}$ autor privilegiou em sua análise as festas operárias (festas de solidariedade que expressam a consciência de classe). Ele procurou demonstrar a hipótese construída por Ecléa Bosi, segundo a qual a "cultura popular é a única que se realiza na militância ou então se atrofia" $"$.

As observações de Beltrão, Bosi e Ribeiro Júnior pertencem a uma conjuntura marcada pelos estertores do regime militar. Poucos pesquisadores aventuravam-se a explorar esse tipo de objeto. Os acadêmicos solidários com as classes subalternas concentravam energias na produção de um novo tipo de mídia cidadã.

Com o fim da censura (1975) e a decretação da anistia política (1979), a resistência ao sistema autoritário fazia-se de modo peculiar. A pesquisa-ação tomava o lugar da pesquisa-denúncia ${ }^{18}$. No arcabouço do projeto de transição lenta, gradual e segura dos generais Geisel-Golbery, o mais importante era conscientizar as classes subalternas para a ocupação dos espaços reservados à cidadania $^{19}$.

Isso explica o pequeno volume de estudos sobre o fenômeno da mídia cidadã. Constituem exceções, nesse panorama, o inventário realizado por Marco Morel ${ }^{20}$ a propósito do jornalismo popular nas favelas cariocas e a sistematização das práticas de jornalismo comunitário feita por Ana Arruda Callado, em parceria com Maria Ignez Duque Estrada ${ }^{21}$. São documentos que atestam o lento desabrochar da cidadania nas zonas periféricas das grandes metrópoles.

Pertencem também a essa conjuntura os esforços de reflexão coletiva sobre a construção de alternativas à mídia hegemônica, catalisando as aspirações da cidadania e fomentando a intervenção de novos sujeitos emissores. Duas associações nacionais ocupam a vanguarda desse movimento. A Sociedade Brasileira de Estudos Interdisciplinares da Comunicação dedica a primeira edição dos seus Cadernos Intercom à revisão das experiências e à proposta de formatos adequados ao jornalismo popular ${ }^{22}$, além de privilegiar a contra-informação no
14. MARQUES DE MELO, José. Comunicação \& libertação. Petrópolis: Vozes, 1981.

15. BELTRÃO, Luiz. Folkcomunicação, a comunicação dos marginalizados. São Paulo: Cortez, 1980. p. 40.

16. RIBEIRO JÚNIOR, Jorge Cláudio Noel. A festa do povo. Petrópolis: Vozes, 1982. p. 12.

17. BOSI, Ecléa. Cultura de massa e cultura popular. Petrópolis: Vozes, 1972.

18. Para melhor entender essa conjuntura, vide: MARQUES DE MELO, José; GO$\mathrm{BBI}$, Maria Cristina. Gênese do pensamento comunicacional latino-americano: da pesquisa-denúncia ao pragmatismo utópico. São Bernardo do Campo: Umesp/FAl, 2004.

19. Esse capítulo da nossa história recente está documentado em MARQUES DE MELO, José (Org.). Comunicação e transição democrática. Porto Alegre: Mercado Aberto, 1985.

20. MOREL, Marco. Jornalismo popular nas favelas cariocas. Rio de Janeiro: RioArte, 1986.

21. CALLADO, Ana Arruda; ESTRADA, Maria Ignez Duque. Como se faz um jornal comunitário. Petrópolis: Vozes, 1985.

22. Jornalismo popular. Cadernos Intercom, São Paulo: Cortez, v. 1, n. 1, p. 3-78, 1982. 
23. LINS DA SILVA, Carlos Eduardo. Comunicação, hegemonia e contrainformação. São Paulo: Cortez/Intercom, 1982.

24. SOARES, Ismar; PUNTEL, Joana; FLEURI, Reinaldo. Direitos humanos: um desafio à comunicação. São Paulo: Paulus, 1983.

25. GOMES, Pedro Gilberto; BULIK, Linda; PIVA, Márcia. Comunicação, memória \& resistência. São Paulo: Paulinas, 1989

26. UMESP. Comunicação alternativa e cultura popular. Comunicação \& Sociedade, São Bernardo do Campo, n. 6, 1981.

27. Vide: MARQUES DE MELO, José. História do pensamento comunicacional. São Paulo: Paulus, 2003. p. $272-287$

28. FESTA, Regina; LINS DA SILVA, Carlos Eduardo. Comunicação popular e alternativa no Brasil. São Paulo: Paulus, 1986.

29. SANTORO, Luiz Fernando. A imagem nas mãos: o vídeo popular no Brasil. São Paulo: Summus, 1989. p. 113

30. Vide: FREITAS NOBRE, José. Imprensa e liberdade: os princípios constitucionais e a nova legislação. São Paulo: Summus, 1987.

31. FERREIRA, Maria Nazareth. Imprensa operária no Brasil. São Paulo: Ática, 1988.

32. ARAÚJO, Silvia; CARDOSO, Alcina. Jornalismo \& militância operária. Curitiba: UFPR, 1992

33. RUBIM, Albino. Marxismo, cultura e intelectuais no Brasil. Salvador: UFBA, 1995.

34. MOMESSO, Luiz. Comunicação sindical: limites, contradições, perspectivas. Recife: UFPE, 1997. temário do seu congresso anual ${ }^{23}$. A União Cristã Brasileira de Comunicação Social - UCBC proclama os direitos humanos como um "desafio à comunicação" 24 e reconstitui a memória da resistência durante os anos de chumbo ${ }^{25}$ como alerta para o trabalho das gerações emergentes.

Concomitantemente, o Programa de Pós-Graduação em Comunicação Social da hoje Universidade Metodista de São Paulo incluiu o novo objeto de estudos na sua agenda acadêmica. O ponto de partida foi o lançamento da edição monográfica da revista Comunicação \& Sociedade ${ }^{26}$, focalizando as relações entre a comunicação alternativa e a cultura popular. Na seqüência, três jovens pesquisadores vinculados ao Grupo de São Bernardo ${ }^{27}$, mas que também estavam na vanguarda das instituições acima referidas, ampliam o debate sobre a questão. Regina Festa e Carlos Eduardo Lins da Silva ${ }^{28}$ selecionam projetos emblemáticos de comunicação popular e alternativa desenvolvidos no Brasil no período entre 1968 e 1982. Por sua vez, Luiz Fernando Santoro inventaria criticamente o movimento brasileiro de vídeo popular, realçando sua colaboração para que "as classes populares possam expressar a sua própria visão de mundo, informar-se, registrar a sua história” ${ }^{29}$.

Cresce na fase posterior à Constituinte de 1988 o interesse acadêmico pelo protagonismo da cidadania, ocupando espaços possíveis no complexo midiático. Popularmente conhecida como Constituição Cidadã, a nossa carta magna ampliou consideravelmente os direitos humanos, instituindo diretrizes para garantir o acesso dos cidadãos aos sistemas midiáticos, não apenas como receptores, mas até como emissores. Os bastidores desse episódio estão registrados por um dos seus lúcidos observadores-participantes ${ }^{30}$.

As brechas legalmente instituídas pelo sistema beneficiam justamente o operariado, segmento mais bem organizado e com maior tradição de luta. Através dos sindicatos, e não raro usando subsídios estatais, os trabalhadores urbanos substituem os tradicionais e rudimentares meios de comunicação pelas novas tecnologias de difusão simbólica. Adotando a estratégia rotulada como política de resultados, muitos deles conquistam espaços no aparato legislativo e passam a influir nas decisões nacionais, alcançando até mesmo postos executivos nos governos municipais e estaduais.

Essa transição política mereceu a atenção de um contingente expressivo de pesquisadores da comunicação, alguns mais preocupados com as variáveis históricas do processo, desentranhando as raízes da mídia operária, como Ferreira $^{31}$, Araújo \& Cardoso ${ }^{32}$ e Rubim ${ }^{33}$; outros mais interessados em conhecer o desempenho da moderna mídia sindical, como Momesso ${ }^{34}$, Ferreira \& equipe ${ }^{35}$ e Santiago \& Gianotti ${ }^{36}$.

Geralmente desencadeadas nos pátios ou portões das fábricas, as lutas sindicais repercutiam nas comunidades habitadas pelos operários. Sua correia de transmissão era quase sempre a imprensa mantida pelas comunidades eclesiais de base ou instituições congêneres das periferias metropolitanas. Esse filão surpreendente da mídia cidadã foi desvendado por Gomes ${ }^{37}$. Valendo-se da metodologia da observação participante, ele penetra no âmago dos processos 
comunicacionais em uma paróquia do bairro de São Miguel Paulista. E desentranha as relações conflituosas entre lideranças sindicais, partidárias e religiosas nos bastidores da produção de um jornal comunitário.

\section{COMBATES E BATALHAS}

Percebe-se claramente, nesta revisão bibliográfica, que a pesquisa do exercício midiático da cidadania reduziu-se historicamente à mídia segmentada, classista ou periférica.

Por isso mesmo, ganha significação o livro de Jorge Maranhão, focalizando o "papel da mídia no despertar da cidadania"38. Refletindo sobre o ofício de publicitário, ele examina criticamente a ação de empresas, órgãos públicos e entidades da sociedade civil, iluminando iniciativas que favorecem a qualidade de vida dos cidadãos e refugando aquelas que prejudicam os interesses coletivos. Seu ponto de partida é a compreensão do estágio em que se encontra a cidadania brasileira, seus canais de expressão das reivindicações comunitárias e o tratamento que essas demandas merecem da mídia hegemônica.

Contudo, o autor demonstra o seu ceticismo quanto ao papel das elites no fortalecimento da cidadania. Esse desprezo pelas camadas sociais que constituem a base da nossa pirâmide social explica a natureza episódica, residual e intermitente dos espaços dedicados ao povo em movimento, vale dizer, à construção da nossa cidadania, na grande mídia. Em seu artigo Omissão das classes subalternas $e$ da América Latina nas notícias diárias de quatro jornais paulistas, Maria Otilia Boccini demonstra claramente essa tendência ${ }^{39}$. Esses espaços vão se ampliando à medida que os cidadãos organizados em associações de moradores, clubes de mães, sociedades beneficentes e mutirões cívicos arregimentam suas próprias forças.

Cicília Peruzzo ${ }^{40}$ iniciou o resgate crítico dessa participação dos agentes midiáticos na construção da cidadania. Sua conclusão reforça a esperança de que a utopia da mídia cidadã deixe de ser quimera (ilusão, fantasia), concretizando-se através de processos capazes de evidenciar que "o homem e a mulher encerram a potencialidade de ser sujeitos da história" ${ }^{41}$. Assumindo a parte que lhes compete nessa caminhada, Peruzzo \& Almeida ${ }^{42}$ e Peruzzo ${ }^{43}$ vêm mobilizando a comunidade acadêmica no sentido de observar e refletir sobre as experiências de comunicação para a cidadania. E também para reconhecer quais vozes cidadãs tornam-se emblemáticas, motivando os novos sujeitos desse processo.

Cogo $^{44}$ atesta a pujança das rádios comunitárias, descrevendo o caso da Rádio Popular Lagoa, de Belo Horizonte. Bazi ${ }^{45}$ apresenta um mapa da televisão regional paulista, focalizando as ações conjuntas com a comunidade. Fernandes ${ }^{46}$ explica como se estrutura a pequena imprensa catarinense, destacando a força do jornal do interior. Por sua vez, Dornelles ${ }^{47}$ investiga os mecanismos através dos quais os jornais que circulam em cidades do interior gaúcho estabelecem sintonia com as demandas comunitárias. Trata-se do mesmo universo que havia sido palmilhado por Marques de Melo \& Queiroz $^{48}$ no caso da imprensa paulista, em que procuraram entender as conexões entre local, regional, nacional e global.
35. FERREIRA, Maria $\mathrm{Na}$ zareth (Org.). O impasse da comunicação sindical. São Paulo: CBELA, 1995.

36. SANTIAGO, Claudia; GIANOTTI, Vito. Comunicação sindical: falando para milhões. Petrópolis: Vozes, 1997.

37. GOMES, Pedro Gilberto. O jornalismo alternativo no projeto popular. São Paulo: Paulinas, 1990.

38. MARANHÃO, Jorge. Mídia e cidadania. Rio de Janeiro: Topbooks, 1993.

39. Vide: MARQUES DE MELO, José (Org.). Ideologia, cultura e comunicação no Brasil. São Bernardo do Campo: Umesp, 1982. p. 21-48.

40. Peruzzo, Cicília. Comunicação nos movimentos populares: a participação na construção da cidadania. Petrópolis: Vozes, 1998.

41. Ibid., p. 23.

42. PERUZZO, Cicília; ALMEIDA, Fernando. Comunicação para a cidadania. Salvador: Uneb; São Paulo: Intercom, 2003.

43. PERUZZO, Cicília. Vozes cidadãs. São Paulo: Angellara, 2004.

44. COGO, Denise. No ar... uma rádio comunitária. São Paulo: Paulinas, 1988.

45. BAZI, Rogério. TV regional. Campinas: Alínea, 2001.

46. FERNANDES, Mario Luiz. A força do jornal do interior. Itajaí: Univali, 2003.

47. DORNELLES, Beatriz. Jornalismo "comunitário" em cidades do interior. Porto Alegre: Sagra-Lusatto, 2004.

48. MARQUES DE MELO, José; QUEIROZ, Adolpho. Identidade da imprensa brasileira no final do século. São Bernardo do Campo: Umesp, 1998. 
49. LIMA, M. Fátima; PRIETO, Nelson; FERREIRA, Lucrecia. Mídia digital e educação: tudo ao mesmo tempo agora o tempo todo... In: BARBOSA FILHO, André; CASTRO Cosette; TOME, Takashi. Mídias digitais. São Paulo: Paulinas, 2005.

50. BARBOSA FILHO, André: CASTRO, Cosette. A inclusão digital como forma de inclusão social. In: BARBOSA FILHO, André; CASTRO, Cosette; TOME, Takashi. Mídias digitais. São Paulo: Paulinas, 2005

51. BENJAMIN, Roberto. Folkcomunicação no contexto de massa. João Pessoa: UFPB, 2000; id. Folkcomunicação na sociedade contemporânea. Porto Alegre: Comissão Gaúcha de Folclore, 2004

52. MARQUES DE MELO, José; KUNSCH, Waldemar. De Belém a Bagé: imagens midiáticas do natal brasileiro. São Bernardo do Campo: Umesp, 1998.

53. MARQUES DE MELO, José; LUYTEN, Joseph; CASTELO BRANCO, Samantha. Imagens midiáticas do carnaval brasileiro. Anuário Unesco/Umesp de Comunicação Regional, 4 (113-202), São Bernardo do Campo: Umesp, 2000.

54. TRIGUEIRO, Osvaldo. O São João de Campina Grande na mídia. Anuário Unesco/Umesp de Comunicação Regional, 5 (135150), São Bernardo do Campo: Umesp, 2001.

55. HOHLFELDT, Antonio. A imagem da política e dos políticos na perspectiva da Folkcomunicação. Anuário Unesco/Umesp de Comunicação Regional, 8 (59-78), São Bernardo do Campo: Umesp, 2004.

A utopia brasileira da mídia cidadã começa, portanto, a adquirir concretude, ultrapassando o universo da tipografia e das telecomunicações para ingressar no ciberespaço. Lima, Prieto \& Ferreira ${ }^{49}$ sinalizam as potencialidades da mídia digital para a educação cidadã, enquanto Barbosa Filho \& Castro discutem as perspectivas de acesso das comunidades periféricas à cibercultura, reafirmando "a inclusão digital como forma de inclusão social"

Tendência idêntica de atualização histórica opera-se no âmbito da folkcomunicação. Nota-se, por um lado, a transmutação dos fluxos mediadores desencadeados pelos agentes folk, dentro das comunidades em que atuam, sob o impacto contínuo da mídia massiva, como bem o interpreta Benjamin ${ }^{51}$. Por outro lado, verifica-se uma espécie de contrafluxo folkmidiático, caracterizado pela apropriação que as indústrias culturais fazem das manifestações folclóricas. Fenômenos dessa natureza foram documentados e analisados por Marques de Melo \& Kunsch ${ }^{52}$ em relação aos festejos natalinos; por Marques de Melo, Luyten \& Castelo Branco ${ }^{53}$ no que diz respeito ao carnaval; por Trigueiro ${ }^{54}$, no caso das celebrações juninas, e por Hohlfeldt ${ }^{55}$, no tocante à propaganda política em tempo de eleições.

Entretanto, o caminho a percorrer demanda esforço, perseverança e determinação. Trata-se de batalha cuja vitória depende fundamentalmente da vontade dos sujeitos que estão na vanguarda da sociedade política. Mas a sociedade civil e a comunidade acadêmica podem exercer influência, acelerando o processo através de estudos e reflexões capazes de sensibilizar e convencer os que tomam decisões nas estruturas de poder.

Resumo: A simultaneidade de sistemas midiáticos na sociedade brasileira, um massivo (hegemônico) e outro popular (contra-hegemônico), constitui um paradoxo que desafia os pesquisadores da área de Comunicação. Revisando o itinerário percorrido pelos pensadores brasileiros para elucidar a questão, surge naturalmente o conceito de mídia cidadã como ideal utópico capaz de estabelecer convergências entre os dois sistemas midiáticos ainda incomunicados.

Palavras-chave: midiologia, cidadania, hegemonia, utopia, Brasil.
Abstract: The evidence of simultaneous media systems in the structure of the Brazilian society, one mass oriented (hegemonic) and the other grass root oriented (antagonist), represents a paradox faced by the communication researchers community. The state of art based on the Brazilian communication thought naturally suggests the concept of citizenship media as utopian goal in order to build convergences between both systems yet speechless.

Keywords: media research, citizenship, hegemony, utopia, Brazil. 